\title{
Особенности наночастиц ZnCdS, синтезированных в различных растворителах
}

\author{
() А.Г. Кязым-заде, М.А. Джафраров ॠ, Е.Ф. Насиров, С.А. Джахангирова, Р.С. Джафарли
}

Бакинский государственный университет, Az-1148 Баку, Азербайджан

ฯ E-mail: maarif.jafarov@mail.ru

(Получена 27 апреля 2016 г. Принята к печати 21 сентября 2016 г.)

Получены устойчивые коллоидные растворы наночастиц $\mathrm{ZnCdS}$ диаметром 3-6нм в поливиниловом спирте, полиэтиленгликоле и $\mathrm{H}_{2} \mathrm{O}$. Размер синтезированных наночастиц не зависел от соотношения прекурсоров. Показано, что стабилизация частиц обусловлена зарядовым фактором устойчивости и достигается в отсутствие дополнительных стабилизирующих добавок. Синтезированные квантовые точки $\mathrm{ZnCdS}$ излучают в широкой области спектра 450-600 нм.

DOI: $10.21883 /$ FTP.2017.04.44339.8308

\section{1. Введение}

Наночастицы халькогенидов переходных металлов соединений группы $\mathrm{A}^{\mathrm{II}} \mathrm{B}^{\mathrm{VI}}$ (квантовые точки) в дисперсиях и аморфных матрицах представляют большой интерес как объекты, оптические свойства которых целиком зависят от вида, размеров и дефектности. Так, при изменении размера частиц $\mathrm{ZnS}, \mathrm{CdS}, \mathrm{CdSe}$ и $\mathrm{CdTe}$ от 2 до 5 нм положение максимумов их спектров поглощения и флуоресценции может изменяться более чем на 100 нм, перекрывая диапазон от ближней ультрафиолетовой (УФ) до инфракрасной (ИК) области спектра. Композитные материалы на основе полимеров (полиметилметакрилат, поли-2-гидроксиэтилметакрилат и др.), активированные квантовыми точками (КТ), могут использоваться в качестве конвертеров излучения в линзах светодиодов, люминесцентных солнечных концентраторах, декоративных элементах и других материалах и устройствах $[1,2]$. Одно из направлений использования КТ - био- и химические сенсоры [3], где они благодаря бо́льшим фотостабильности, эффективности излучения и чувствительности могут заменить другие материалы, например, органические красители. Повышение квантовой эффективности излучения и стабильности КТ (например, легирование $\mathrm{ZnS}$ марганцем [4,5]), позволяет использовать такие материалы в электролюминесцентных устройствах в сочетании с органическими материалами. Кроме уникальных оптических характеристик, КТ полупроводников $\mathrm{A}^{\mathrm{II}} \mathrm{B}^{\mathrm{VI}}$ могут проявлять фотокаталитическую активность: например, наночастицы $\mathrm{CdS}$ могут использоваться в качестве катализаторов разложения органических загрязнителей воды [6]. КТ полупроводников также являются перспективными материалами для фотокаталитического разложения воды с целью синтеза $\mathrm{H}_{2}$. Коллоидные растворы КТ полупроводников без принятия специальных мер, как правило, термодинамически нестабильны, что и приводит к их агломерации до микрометровых размеров, расслоению, выпадению в осадок и отсутствию размерно-зависимых свойств. Для предотвращения самопроизвольной коагуляции синтезируемые наночастицы стабилизируют, применяя различные вещества, в том числе высокомолекулярные соединения. В результате стерической стабилизации высокомолекулярного соединения КТ окружены предохраняющим барьером, представляющим собой сплошной слой сольватированных полимерных цепей достаточных размеров [7], коллоидная система становится устойчивой, пока не разрушится полимерное окружение. На сегодняшний день существует большое количество химических способов и подходов к стабилизации КТ полупроводников группы $\mathrm{A}^{\mathrm{II}} \mathrm{B}^{\mathrm{VI}}$, и все они, как правило, сводятся к пассивации поверхности наночастиц путем введения дополнительного стабилизирующего компонента. Это может ограничивать круг практического использования создаваемых систем. В связи с этим актуальна задача поиска новых прекурсоров для получения устойчивых коллоидов халькогенидов переходных металлов в различных растворителях без введения в них дополнительных стабилизирующих компонентов, а также исследование влияния параметров процесса синтеза и природы растворителя на размер и спектрально-люминесцентные свойства синтезируемых КТ.

Целью данной работы являлось сравнение спектрально-люминесцентных свойств КT ZnCdS, синтезированных в различных растворителях, а также изучение влияния растворителя и соотношений концентраций прекурсоров на размер частиц и устойчивость коллоидов.

\section{2. Эксперимент}

Наночастицы $\mathrm{ZnCdS}$ получали при взаимодействии предварительно синтезированных ацетатов кадмия и цинка, $\left(\mathrm{CH}_{3} \mathrm{COO}\right)_{2} \mathrm{Cd},\left(\mathrm{CH}_{3} \mathrm{COO}\right)_{2} \mathrm{Zn}$ соответственно, с сульфидом натрия $\left(\mathrm{Na}_{2} \mathrm{~S}\right)$, растворенным в требуемом растворителе (поливиниловый спирт, полиэтиленгликоль, дистиллированная вода) при интенсивном механическом перемешивании.

Спектры поглощения в видимой и ближней УФ области измерялись с использованием кварцевых кювет с 
длиной оптического пути 1-10 мм на спектрофотометре Cary 100 (Varian) в интервале 200-900 нм с шагом 1 нм в диапазоне оптических плотностей до 3 . Спектры флуоресценции регистрировали на спектрофлуориметре в диапазоне $360-820$ нм с шагом 1 нм в режиме „на отражение“ для уменьшения влияния перепоглощения. Средний радиус частиц $\mathrm{ZnCdS}$ оценивали из спектров поглощения по краю полосы поглощения (край Урбаха) по изменению ширины запрещенной зоны $\left(\Delta E_{g}\right)$ относительно значения для объемного кристалла с использованием приближения эффективных масс согласно [8]. Размер частиц определялся из светлопольных изображений (микрофотографий), полученных на просвечивающем электронном микроскопе (ПЭМ) CM12 (Philips), коллоидные растворы наносились на медные сетки с аморфным углеродным покрытием, высушивались и исследовались с различным увеличением при ускоряющем напряжении до 120 кВ. Распределение частиц по размерам проводилось по выборкам не менее 500 частиц, полученным из 3-5 микрофотографий. Для некоторых образцов данный метод не позволял определить размер частиц из-за их малой контрастности или размера, выходящего за диапазон измерительных возможностей прибора.

\section{3. Результаты и их обсуждение}

При осаждении наночастиц $\mathrm{ZnCdS}$ вследствие воздействия $\mathrm{H}_{2} \mathrm{~S}$ на реакционную смесь частицы сразу выпадали в виде грубодисперсного осадка. Зарядовый фактор устойчивости для данной реакционной системы был нехарактерен. Оставался открытым вопрос об устойчивости КТ в других растворителях при использовании прекурсоров ацетата $\mathrm{Cd}$ и $\mathrm{Zn}$ без механизма полимеризации, а также о возможности получения однородных композитов с флуоресцирующими наночастицами в других полимерах [9].

По описанной выше методике была получена серия коллоидных растворов в трех растворителях. Вода $\mathrm{H}_{2} \mathrm{O}$ является сильно полярным протонным растворителем с высокой диэлектрической проницаемостью $\varepsilon=78$ и не способна проявлять стабилизирующие свойства по отношению к КТ группы $\mathrm{A}^{\mathrm{II}} \mathrm{B}^{\mathrm{VI}}$. Поливиниловый спирт (ПВС) не способен к полимеризации, что дает возможность оценить стабильность синтезируемых коллоидов во времени. В системе с полиэтиленгликолем (ПЭГ) также может присутствовать адсорбционно-сольватный фактор устойчивости. Синтезированные по описанной выше методике коллоидные растворы наночастиц ZnCdS были стабильны и не меняли своих оптических свойств после их хранения в темноте в течение нескольких суток. При облучении растворов наблюдалась фотокоррозия наночастиц во всех растворителях. При хранении коллоидных растворов $\mathrm{ZnCdS} / \mathrm{H}_{2} \mathrm{O}$ более 7 суток происходит выпадение наночастиц $\mathrm{ZnCdS}$ в осадок. При механическом редиспергировании частицы равномерно распределяются по всему объему и дисперсия остается
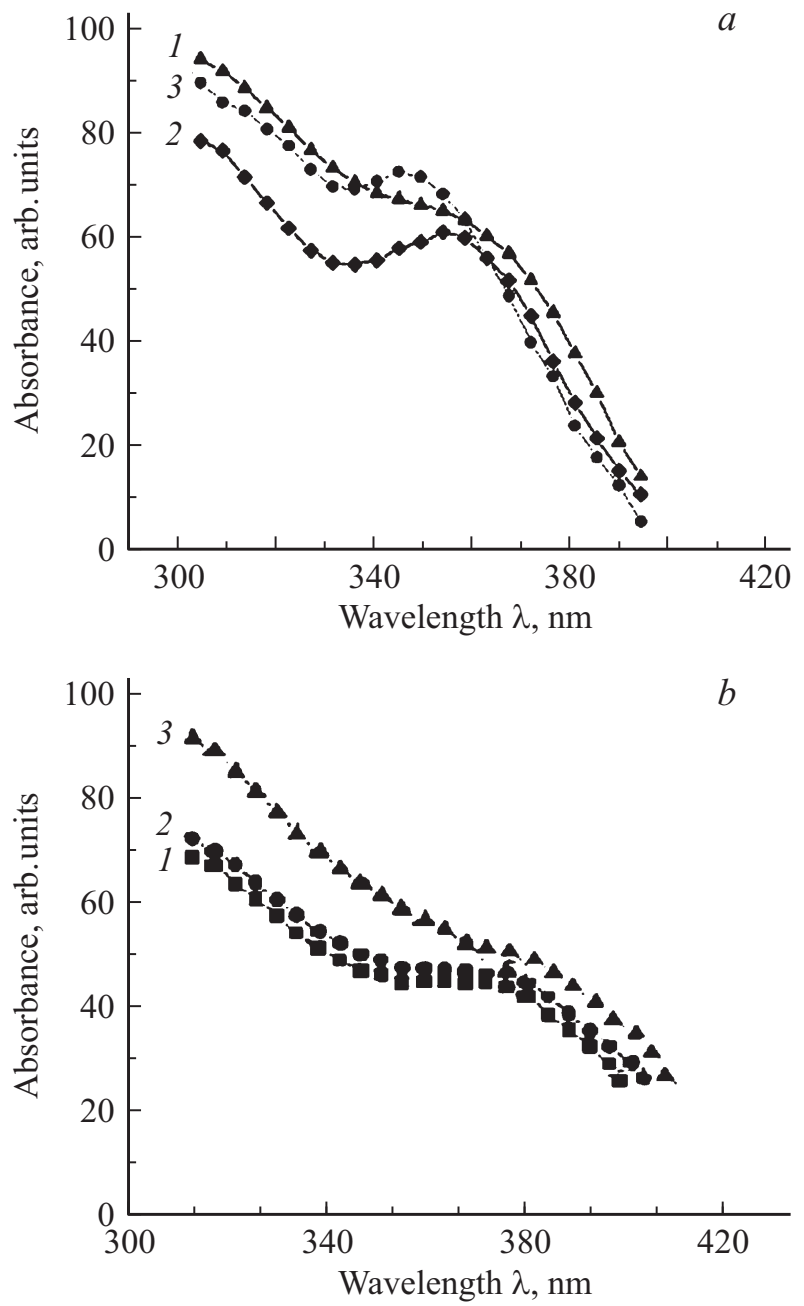

Рис. 1. Спектры поглощения $\mathrm{ZnCdS}$ в $\mathrm{H}_{2} \mathrm{O}$ (1), ПВС (2) и ПЭГ (3). Соотношение $\left(\mathrm{CH}_{3} \mathrm{COO}\right)_{2} \mathrm{Cd}, \mathrm{Zn}: \mathrm{Na}_{2} \mathrm{~S}-1: 1$ (a) и $1: 4(b)$.

стабильной такой же длительный промежуток времени. Это говорит о том, что коллоидный раствор $\mathrm{ZnCdS} / \mathrm{H}_{2} \mathrm{O}$ в меньшей степени обладает седиментационной устойчивостью, нежели коагуляционной.

На рис. 1 приведены спектры поглощения наночастиц ZnCdS в различных растворителях. Анализ спектров поглощения для разных соотношений концентраций прекурсоров, в частности значительное увеличение интенсивности поглощения в максимуме экситонного пика при увеличении концентрации $\mathrm{Na}_{2} \mathrm{~S}$ и неизменной концентрации ацетата $\mathrm{Cd}$, показывает, что при эквимолярном соотношении прекурсоров кадмия, цинка и серы $\left(\left(\mathrm{CH}_{3} \mathrm{COO}\right)_{2} \mathrm{Cd}, \mathrm{Zn}: \mathrm{Na}_{2} \mathrm{~S}\right)$ в среде не происходит их полного химического взаимодействия. Таким образом, в растворе наряду со сформировавшимися KT ZnCdS остается не прореагировавший ацетат $\mathrm{Cd}, \mathrm{Zn}$. Четырехкратный избыток ионов серы по отношению к кадмию приводит к эффективному формированию большей концентрации наночастиц во всех растворителях (рис. $1, b$ кривая 3 ). Форма первого экситонного пика в спектре поглощения, 


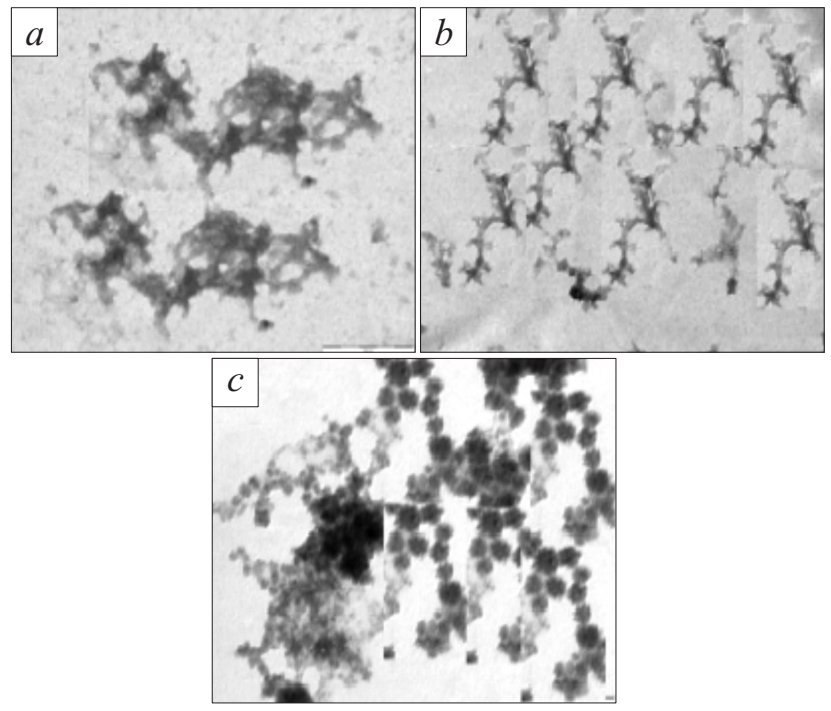

Рис. 2. ПЭМ-изображения дисперсий $\mathrm{ZnCdS}$ в $\mathrm{H}_{2} \mathrm{O}(a)$, ПВС $(b)$ и ПЭГ (c). Соотношение $\left(\mathrm{CH}_{3} \mathrm{COO}\right)_{2} \mathrm{Cd}: \mathrm{Na}_{2} \mathrm{~S}-1: 1$.

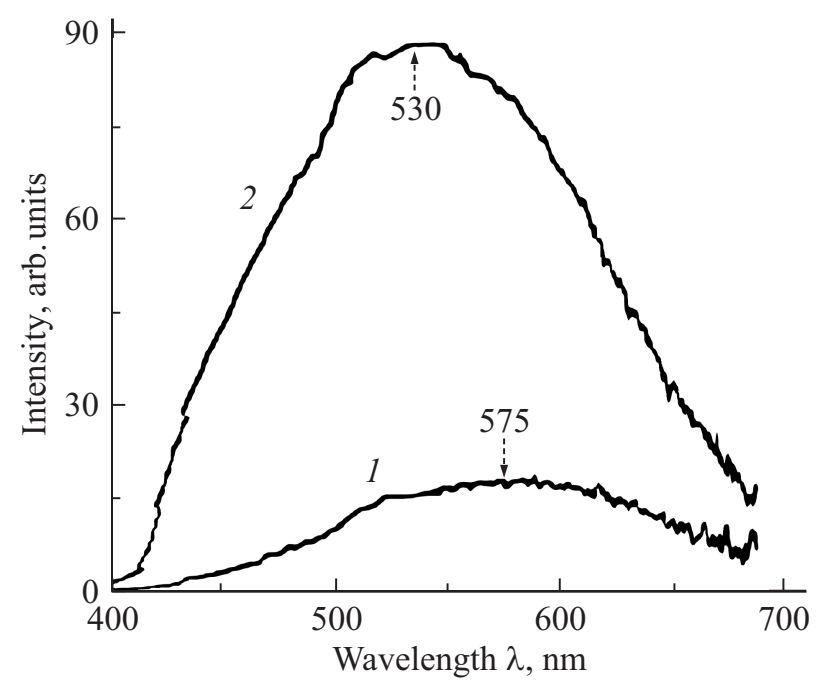

Рис. 3. Спектры люминесценции $\mathrm{ZnCdS}$ в ПВС (1) и ПЭГ (2). Длина волны возбуждения $350 \mathrm{нм}$, соотношение $\left(\mathrm{CH}_{3} \mathrm{COO}\right)_{2} \mathrm{Cd}, \mathrm{Zn}: \mathrm{Na}_{2} \mathrm{~S}-1: 1$

по которой характеризуется дисперсность наночастиц в системе, позволяет отметить, что при избытке серы в ПВС частицы в системе более монодисперсны, чем при эквимолярном соотношении прекурсоров или избытке кадмия, при этом край полосы поглощения не сдвигается и размер частиц остается постоянным.

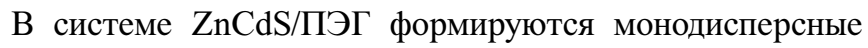
частицы для всех соотношений концентраций прекурсоров, что сопровождается выраженным экситонным пиком. При избытке серы максимум полосы поглощения незначительно сдвигается в длинноволновую область спектра (рис. $1, b$, кривая 3 ), что говорит о незначительном укрупнении наночастиц. При синтезе КТ в воде формируются самые крупные полидисперсные частицы, максимум экситоного пика не выражен и находится в области $370 \mathrm{Hм}$.

Из спектров поглощения (рис. 1) был рассчитан средний диаметр частиц $\mathrm{ZnCdS}$. Диаметр частиц в ПВС и ПЭГ составляет $\sim 5$ нм и почти не зависит от соотношения концентраций осадителя и прекурсора. Для системы $\mathrm{ZnCdS} / \mathrm{H}_{2} \mathrm{O}$ при увеличении концентрации сероводорода формируются более крупные частицы, от 5.5 до 8.0 нм. Данные расчетов диаметра частиц из спектров поглощения хорошо согласуются с результатами ПЭМ (рис. 2). Из рис. 2 видно, что наночастицы собраны в агломераты крупных размеров. Эти данные подтверждают результаты измерений непосредственно в растворах методом динамического рассеяния света. Данные светорассеяния характеризуют размер агломератов - скопления отдельных частиц, разделенных адсорбированными на них ионами $\mathrm{CH}_{3} \mathrm{COO}^{-}$и $\mathrm{NaS}^{-}$, препятствующими их слипанию.

Наиболее крупные агломераты $\mathrm{ZnCdS}$ (до 1 мкм) наблюдаются в мономере ПЭГ, что, вероятно, связано с наличием в среде полимерных цепочек, так как растворитель использовался без предварительной перегонки. Дзета-потенциал наночастиц во всех дисперсиях отрицательный, величина $230 \mathrm{MB}$ (пороговое значение, при котором начинается процесс коагуляции $\mathrm{ZnCdS}$ ).

Исследования излучательных свойств дисперсий показали, что в спектрах флуоресценции $\mathrm{ZnCdS} /$ ПВC и $\mathrm{ZnCdS/ПЭГ} \mathrm{(рис.} \mathrm{3)} \mathrm{отсутствуют} \mathrm{полосы,} \mathrm{связанные} \mathrm{с}$ размерно-зависимыми межзонными переходами, так называемой „объемной“ люминесценцией, и наблюдается широкая полоса излучения в диапазоне 400-700нм. Излучение относится к так называемой „поверхностной люминесценции, обусловленной излучательной релаксацией через дефектные уровни кристаллической решетки $\mathrm{ZnCdS}$, а также влиянием адсорбированных на поверхности частиц ионов $\mathrm{CH}_{3} \mathrm{COO}^{-}$и $\mathrm{NaS}^{-}$. Флуоресценция в системе $\mathrm{ZnCdS} / \mathrm{H}_{2} \mathrm{O}$ не наблюдалась.

Причин этого может быть несколько - например, наличие гасящих флуоресценцию $\mathrm{CdS}$ примесей, таких как ионы железа, или других каналов быстрой безызлучательной релаксации энергии возбуждения в частицах.

Для $\mathrm{ZnS}$ наблюдается аналогичная $\mathrm{ZnCdS}$ зависимость изменения интенсивности поглощения дисперсий от соотношения концентрации прекурсоров, что подтверждает неполное протекание реакции при эквимолярном соотношении прекурсоров цинка и серы $\left(\mathrm{CH}_{3} \mathrm{COO}\right)_{2} \mathrm{Zn}: \mathrm{Na}_{2} \mathrm{~S}$. Не наблюдалось также зависимости размера частиц от увеличения концентрации сероводорода.

В отличие от наночастиц сульфида кадмия, по данным измерения методом динамического светорассеяния KT ZnS во всех дисперсиях не образуют больших агломератов. Для КТ ZnS в ПВС и ПЭГ наблюдается излучение в ближнем УФ и видимом диапазоне спектра (350-500 нм), причем в спектре проявляется как „объемная“, связанная с межзонными переходами 
и зависящая от размера частиц, так и „поверхностная“, связанная с дефектами, флуоресценция.

\section{4. Заключение}

Получены устойчивые коллоидные растворы наночастиц $\mathrm{ZnCdS}$ диаметром 3-6нм в ПВС, ПЭГи $\mathrm{H}_{2} \mathrm{O}$. Стабилизация частиц в реализованной схеме синтеза обусловлена зарядовым фактором устойчивости и достигается в отсутствие дополнительных стабилизирующих добавок. Устойчивые дисперсии КТ $\mathrm{ZnS}$ в ПВС и ПЭГ могут непосредственно использоваться как в качестве широкополосных флуоресцирующих дисперсий и для дальнейших исследований квантово-размерных оптических свойств, так и быть перенесены в другие растворители, в том числе мономеры для получения оптически прозрачных композитных материалов.

\section{Список литературы}

[1] J. Schrier, D.O. Demchenko, L.-W. Wang. Nano Lett., 7 (8), 2377 (2007).

[2] K. Ichino, K. Ueyama, M. Yamamoto, H. Kariya, H. Miyata, H. Misasa, M. Kitagawa, H. Kobayashi. J. Appl. Phys., 87, 4249 (2000).

[3] S.M.A. Durrani, A.M. Al-Shukri, A. Iob, E.E. Khawaja. Thin Sol. Films, 379, 199 (2000).

[4] V. Dimitrova, J. Tate. Thin Sol. Films, 365, 134 (2000).

[5] J. Cheng, D.B. Fan, H. Wang, B.W. Liu, Y.C. Zhang, H. Yan. Semicond. Sci. Technol., 18, 676 (2003).

[6] P. Roy, J.R. Ota, S.K. Srivastava. Thin Sol. Films., 515, 1912 (2006).

[7] H.H. Afifi, S.A. Mahmoud, A. Ashour. Thin Sol. Films, 263, 248 (1995).

[8] B. Elidrissi, M. Addou, M. Regragui, A. Bougrine, A. Kachouane, J.C. Bernede. Mater. Chem. Phys., 68, 175 (2001).

[9] B. Bhattacharjee, D. Ganguli, K. Iakoubovskii, A. Stesmans, S. Chaudhuri. Bull. Mater. Sci., 25 (3), 175 (2002).

Редактор Л.В. Шаронова

\section{Features of ZnCdS nanoparticles, synthesized in various soivents}

A.G. Kyazym-zade, M.A. Jafarov, E.F. Nasirov,

C.A. Jahangirova, R.S. Jafarli

Baku State University,

Az-1148 Baku, Azerbaijan

Abstract Stable colloidal solutions of $\mathrm{ZnCdS}$ nanoparticles with of 3-6 nm diameter in polyvinyl alcohol, polyethylene glycol and $\mathrm{H}_{2} \mathrm{O}$ have been obtained. The size of the synthesized nanoparticles was not dependent on the ratio of the precursors. It was shown that stabilization of the particles was caused by the charge factor of stability and achieved in the absence of further stabilizing additives. Synthesized $\mathrm{ZnCdS}$ quantum dots emitted in the broad spectral range $450-600 \mathrm{~nm}$. 